\title{
PKM Bagi Kelompok Peternak Babi Dalam Pengolahan Limbah Kotoran Menjadi Bio Gas Di Desa Banyuraden Kecamatan Gamping Kabupaten Sleman
}

\author{
Tri Yuniastuti ${ }^{1}$, Ilmardani Rince Ramli ${ }^{2}$ \\ Program Studi Arsitektur, Fakultas Teknik UWM \\ Program Studi Teknik Industri, Fakultas Teknik UWM \\ E-mail: triyuni3@gmail.com
}

\begin{abstract}
Problems arising from pigs that are not managed properly include dirty environmental conditions, strong odors caused by feces left open and pollution of river water flowing. This can disturb residents around the farm because they feel disturbed. This problem is faced by partners, namely the Pig Farming Group in Sanggrahan, Banyuraden village, Gamping sub-district, Sleman district.

To create a clean and healthy environment, one of the solutions is to process livestock waste into bio-gas, namely methane gas (CH4) which can be fueled by making bio-digester in the form of a tube to capture biogas from livestock manure that is flowed into it.Through PKM activities, counseling is done to pig farmers about the construction of sewage channels and bio-digester, then it is applied to one group of cages. For the support of community participation, especially pig farmers in the form of space, time and energy, sewage and bio-digester channels can be realized that can produce bio-gas and liquid and solid fertilizers.

The construction of sewage channels and the use of bio-digester are expected to reduce environmental problems and social conflicts and be economically beneficial because they can utilize biogas as a new energy source for farmers and surrounding communities so that they can motivate other pig farmers to make it happen.
\end{abstract}

Keywords: environmental problems, waste treatment, bio-digester, bio-gas, fertilizer.

\begin{abstract}
Abstrak
Permasalahan yang timbul akibat usaha ternak babi yang tidak dikelola dengan baik antara lain kondisi lingkungan yang kotor, bau menyengat yang ditimbulkan oleh kotoran yang dibiarkan terbuka serta pencemaran air sungai yang dialiri. Hal ini dapat meresahkan warga di sekitar peternakan karena merasa terganggu. Permasalahan inilah yang dihadapi oleh mitra yaitu Kelompok Ternak Babi di Sanggrahan, desa Banyuraden, kecamatan Gamping, kabupaten Sleman.

Agar tercipta lingkungan yang bersih dan sehat, salah satu solusinya adalah mengolah limbah ternak menjadi bio-gas yaitu gas methan (CH4) yang dapat menjadi bahan bakar dengan membuat bio-digester berupa tabung untuk menangkap bio-gas dari kotoran ternak yang dialirkan ke dalamnya. Melalui kegiatan PKM, dilakukan penyuluhan kepada peternak babi tentang pembuatan saluran limbah dan bio-digester, kemudian diterapkan pada satu kelompok kandang. Atas dukungan partisipasi masyarakat khususnya peternak babi berupa kesediaan tempat, waktu dan tenaga, terwujudlah saluran limbah dan bio-digester yang dapat menghasilkan bio-gas serta pupuk cair dan padat.

Pembuatan saluran limbah dan pemakaian bio-digester diharapkan dapat mengurangi permasalahan lingkungan dan konflik sosial serta menguntungkan secara ekonomi karena bisa memanfaatkan bio-gas sebagai sumber energi baru bagi kelompok peternak maupun masyarakat sekitarnya sehingga dapat memotivasi para peternak babi lainnya untuk mewujudkannya.
\end{abstract}

Kata Kunci : permasalahan lingkungan, pengolahan limbah, bio-digester, bio-gas, pupuk 


\section{PENDAHULUAN}

\subsection{Latar Belakang Masalah}

Peternak babi di kampung Sanggrahan yang tergabung dalam kelompok Peternak "Rukun" memiliki usaha yang sangat menjanjikan karena tidak banyak mengeluarkan modal untuk biaya operasional, tetapi hasil panen cukup menggiurkan dan permintaan daging babi selalu ada sehingga untuk pemasarannya tidak sulit. Meskipun harga daging babi tidak stabil, namun hingga saat ini usaha ini masih banyak diminati sebagian warga kampung Sanggrahan, Desa Banyuraden, Kecamatan Gamping Kabupaten Sleman. Tercatat ada 29 warga yang beternak babi di pekarangan belakang rumahnya atau di pinggiran sawah.

Produksi ternak babi yang dilakukan oleh warga Sanggrahan dilakukan sangat sederhana dan jumlahnya tergantung modal dan kepemilikan lahan untuk meletakkan kandang. Peternak hanya perlu memelihara induk babi betina, kemudian dikawinkan dengan babi pejantan yang khusus disediakan oleh peternak yang lain. Induk betina yang hamil dirawat dan diberi makan dari limbah makanan yang diambil dari rumah tangga atau restauran. Modal peternak adalah induk babi yang siap kawin dengan menyewa babi pejantan Rp.150.000,- bila pas masa birahi, maka indukan langsung bisa hamil selama 4 bulan kurang 1 minggu. Setelah anak-anak babi lahir dengan jumlah antara 5-12 ekor, butuh waktu 2 bulan untuk merawat anak-anak babi dalam asuhan induknya. Setelah 2 bulan menyusu induknya, anak-anak babi tersebut dipisahkan dari induknya dan induknya siap dikawinkan lagi. Anak-anak babi dibesarkan hingga umur 10 bulan untuk siap dijual. Berat babi pada usia itu sekitar 70-90 kg. Harga jual anak babi bervariasi dan mengalami naik turun tergantung kebutuhan dan pasokan. Harga tertinggi bisa terjual mencapa Rp.29.000/kg.

Usaha peternakan yang sangat menggiurkan ini tidak sebanding dengan dampak lingkungan yang ditimbulkan, baik terhadap lingkungan alam maupun lingkungan sosial masyarakat setempat. Banyak permasalahan yang muncul akibat usaha ternak babi ini, antara lain kondisi lingkungan yang kotor, terutama bagian kandang dan sekitarnya dan bau menyengat yang ditimbulkan oleh kotoran babi yang masih dibiarkan terbuka dan belum dikelola 
dengan baik. Akibat bau kotoran yang menyengat inilah kemudian menjadikan warga di sekitar menjadi resah dan terganggu karena image yang berkembang di masyarakat luas, kampung Sanggrahan kumuh dan bau karena banyak terdapat hewan ternak babi.

Dengan pertimbangan mata pencaharian dan ketersediaan lahan di pekarangan sendiri dan didukung adanya aliran sungai di tengah kampung maka usaha ternak babi ini masih berlanjut hingga saat ini bercampur dengan lingkungan permukiman dengan menyisakan banyak persoalan.

Beberapa penelitian sebelumnya menjadi dasar pertimbangan dalam pengambilan langkah penyikapan dalam program ini Menurut penelitian Wahyuni (2015), biogas adalah campuran gas yang dihasilkan oleh bakteri metanogenik yang terjadi pada material-material yang dapat teruai secara alamiah dalam kondisi anaerobik. Pada umumnya biogas terdiri atas gas metana $\left(\mathrm{CH}_{4}\right) 50$ sampai $70 \%$, gas karbon dioksida $\left(\mathrm{CO}_{2}\right) 30$ sampai 40\%, hidrogen $\left(\mathrm{H}_{2}\right) 5$ sampai $10 \%$, dan gas-gas lainnya dalam jumlah yang sedikit.

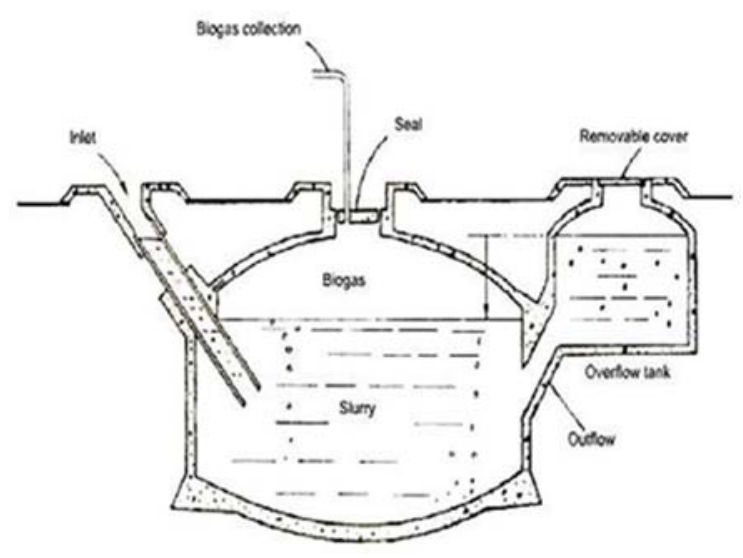

Gambar 1. Instalasi biogas

Sumber : google image, 2016

Gas methan NH4 yang tidak terkelola akan terbang ke udara membentuk rumah kaca. Sedangkan gas methan yang dikelola akan dibuang setelah dibakar. Gas methan dalam bentuk aslinya amat berbau, dengan demikian dapat mengganggu kenyamanan dan kesehatan lingkungan. Kotoran dalam kondisi asli belum dapat dipakai sebagai pupuk, bahkan akan mematikan tanaman. Akan tetapi kotoran ternak yang sudah diproses dan diambil gasnya telah menjadi pupuk yang sempurna berkualitas baik, serta tidak berbau lagi. Selain itu penggunaan biogas akan menggantikan bahan bakar lain. (minyak tanah, gas LPG) yang semakin mahal harganya.

Produksi limbah ternak babi dengan bobot $90 \mathrm{~kg}$ yaitu kurang lebih $7 \mathrm{~kg} /$ hari atau $7,77 \%$ dari berat badan, dengan kandungan Bahan kering berkisar 9\% 
United Nation (1984) dalam Wahyuni (2015) dan Departemen Pertanian Indonesia (2008). Sementara itu, menurut LGED (2006) dalam Simeon (2009), babi dengan berat badan $50 \mathrm{~kg}$ memiliki produksi limbah $5 \mathrm{~kg} /$ hari atau $10 \%$ dari berat badan dengan kandungan bahan kering 20\%.

Berangkat dari penelitian-penelitian tersebut maka melalui Program Kemitraan Masyarakat yang didanai oleh Kemenristekdikti, pengabdi melakukan sejumlah rekayasa sosial dan pembangunan bio-digester untuk mengatasi berbagai masalah.

Dengan demikian, tujuan pengabdian ini adalah meningkatkan pemahaman tentang kesehatan lingkungan yang didukung oleh kebersihan lingkungan kepada seluruh anggota kelompok peternak babi melalui penyuluhan-penyuluhan. Selain itu, dengan penerapan Iptek melalui digester dapat mengurangi dampak keberadaan peternakan di tengah hunian yang menimbulkan permasalahan lingkungan.

\section{METODE PELAKSANAAN}

Tahapan atau langkah-langkah dalam melaksanakan solusi yang ditawarkan untuk mengatasi permasalahan mitra berdasarkan permasalahan yang dihadapi mitra.
Mitra bergerak di bidang ekonomi produktif dan mengarah ke ekonomi produktif, maka metode pelaksanaan kegiatan terkait dengan tahapan pada 2 (dua) bidang permasalahan yang berbeda yang ditangani pada mitra, seperti :

1. Permasalahan dalam bidang produksi.

Proses produksi usaha ternak babi meliputi proses memelihara induk, mengawinkan, menjaga dan merawat selama kehamilan, membantu proses kelahiran dan memelihara anak-anak yang dilahirkan hingga siap untuk dijual. Kegiatan memelihara meliputi menyiapkan kandang, menyediakan pakan dan menjaga kebersihan pakan, ternak dan kandang. Semua kegiatan tersebut diupayakan mempertimbangkan kesehatan peternak, hewan ternak dan lingkungan sekitarnya. Untuk itu perlu diberi penyuluhan tentang usaha ternak yang sehat dengan memperhatikan kebersihan lingkungan.
2. Permasalahan dalam bidang manajemen.

Dalam bidang manajemen bagi peternak khususnya ternak babi antara lain pengelolaan modal, penyediaan bahan pakan, penyediaan papan, operasional pemeliharaan dan pemasaran hasil ternak. 
Persoalan ini diatasi di antaranya dengan penyuluhan tentang manajemen usaha ternak yang tidak mengganggu lingkungan sebaliknya bisa menguntungkan. Kegiatan ini melibatkan partisipasi mitra dalam pelaksanaan program. Pembuatan dilakukan secara gotong royong dengan subsidi bahan dari dana yang diusulkan.

\section{HASIL DAN PEMBAHASAN}

Pelaksanaan program kegiatan PKM diawali dengan pendekatan dan kerja sama mitra. Isu tentang dampak usaha ternak babi sudah sangat marak dibicarakan oleh masyarakat baik di lingkungan RW Sanggrahan maupun di tingkat desa sehingga hal ini sudah menjadi permasalahan umum yang sulit dipecahkan karena menyangkut mata pencaharian warga. Penanganannya harus hati-hati agar tidak menimbulkan konflik antar warga. Untuk membantu mengatasi permasalahan tersebut, dilakukan pendekatan kepada ketua kelompok untuk bekerjasama melalui kegiatan PKM.

Langkah kedua berupa sosialisasi program. Kegiatan ini dilakukan pada acara pertemuan rutin yang diselenggarakan oleh kelompok peternak untuk menyampaikan rencana kegiatan PKM yang akan dilakukan. Selain itu, untuk meminta partisipasi warga berupa kesediaan tempat maupun tenaga untuk penerapan saluran limbah dan biodigester yang akan dibangun.

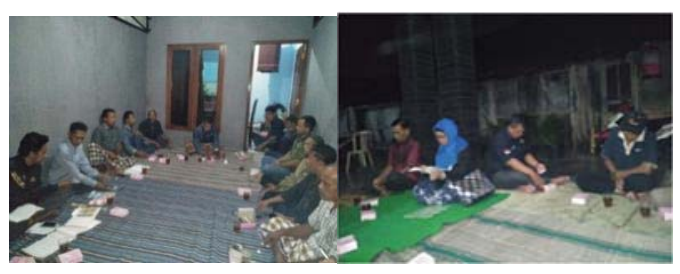

Gambar 2.

Sosialisasi kepada Kelompok Ternak Rukun

Sumber : dokumentasi, 2019

Tahap berikutnya adalah observasi lapangan. Observasi dilakukan secara langsung ke lokasi kandang yang sudah ditunjuk oleh kelompok untuk menanyakan dan mendengarkan keluhan para peternak serta melihat kondisi fisik lingkungan kandang ternak untuk mengetahui permasalahan yang ada. Observasi fisik dilakukan dengan cara dokumentasi gambar situasi kandang dan lingkungan di sekitarnya, ukuran, jarak dan tata letak kandang. Hasil observasi dicatat dan digambarkan denahnya.

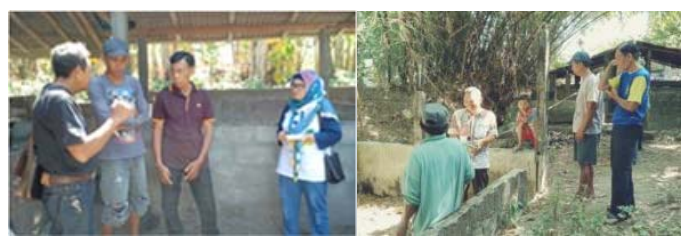

Gambar 3.

Observasi lapangan dan diskusi dengan warga untuk pelaksanaan program.

Sumber : Dokumentasi, 2019

Selanjutnya, perencanaan tempat. Berdasarkan denah dan kondisi lahan, 
ditentukan perletakan fasilitas bio-digester maupun saluran limbahnya. Perencanaan dibuat menyesuaikan kondisi lapangan agar tidak banyak membongkar fasilitas yang sudah ada. Prinsipnya adalah mengubah sistem pembuangan yang sebelumnya terbuka dan langsung disalurkan menjadi tertutup dan dimasukkan ke dalam biodigester.

Persiapan tempat dilakukan dengan menggali tanah untuk tempat membangun fasilitas bio-digester yang berfungsi menampung dan memproses limbah ternak menjadi bio-gas.

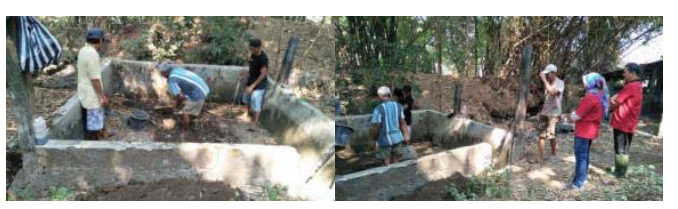

Gambar 4.

Menggali tanah untuk perletakan bio digester.

Sumber : Dokumentasi, 2019

Tahap berikutnya, berupa penyuluhan. Kegiatan ini dilakukan pada pertemuan rutin yang diselenggarakan oleh kelompok peternak. Penyuluhan bertujuan untuk memotivasi anggota kelompok agar bersedia dan dapat mengelola usaha ternak dengan baik dan tidak mengganggu lingkungan, dengan mengolah limbah kotoran menjadi bio-gas dan pupuk cair maupun kandang yang bermanfaat bagi para peternak.

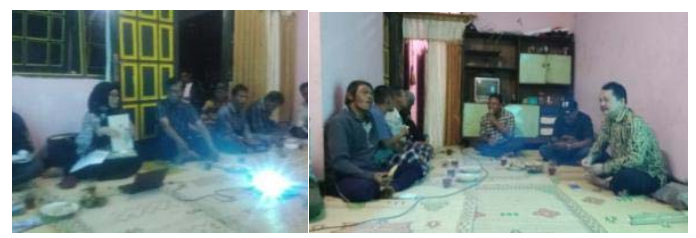

Gambar 5.

Penyuluhan kepada Peternak tentang pengolahan limbah kotoran ternak.

Sumber : Dokumentasi, 2019

Berikutnya, pembuatan bio-digester dan saluran limbah kotoran ternak.

Pemasangan bio-digester dimulai dari susunan dinding bata melingkar dari kedalaman 2,5m dan membentuk dome sebagai tempat pembusukan limbah dan menampung gas methana.

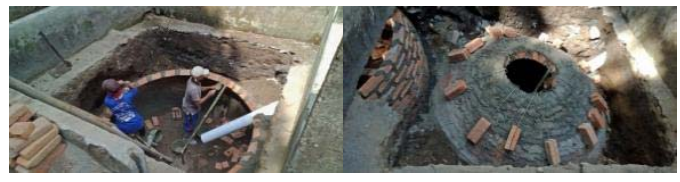

Gambar 6.

Pemasangan bio-digester Sumber : Dokumentasi, 2019

Setelah digester selesai dibangun, maka dibiarkan kering selama 5 hari kemudian dites dengan pengisian air sampai batas tertentu untuk memastikan bahwa tidak terjadi kebocoran. Bagian tabung yang berisi gas harus diurug tanah sehingga tidak muncul di permukaan. Hal ini untuk memperkuat struktur digester dan menjaga suhu tetap sejuk sehingga bakteri di dalam digester tidak mati. 


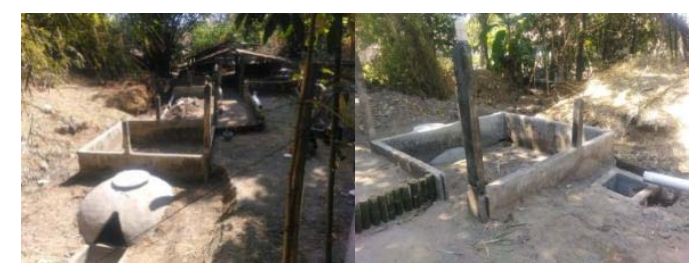

Gambar 7.

Digester sudah diurug dan siap diisi Sumber : Dokumentasi, 2019.

Tahap berikutnya, mengisi bio-digester dengan limbah kotoran ternak. Untuk mempercepat pembentukan gas yang pertama, maka bio digester diisi penuh dengan kotoran ternak sapi yang diampil dari peternakan sapi. Kotoran sapi dicampur air dengan perbandingan 1:1. Proses terbentuknya gas kurang lebih 10 hari. Sambil menunggu proses pembentukan gas, dibuat saluran gas menuju rumah para peternak dengan menggunakan pipa pralon $1 / 2 "$.

Setelah dilakukan sosialisasi dan penyuluhan kepada masyarakat maka para peternak berminat untuk menggunakan biodigester. Berhubung dana terbatas hanya untuk satu instalasi maka pelaksanaaan kegiatan difokuskan pada kandang-kandang yang berkelompok. Kandang-kandang tersebut adalah milik : Bapak Karyono, Bapak Ponoman, Bapak Suhadi dan Bapak Disun Riyadi. Untuk tempat pembuatan digester, Bapak Karyono sudah mengikhlaskan lahannya.
Atas kesepakatan kelompok dan persetujuan pemilik lahan maka saluran limbah dan bio-digester dibangun di lahan Bapak Karyono untuk menampung kotoran limbah babi dari sekitar 20 kandang milik 4 peternak yang berdekatan.

Hasil kegiatan turut ditunjukkan dengan meningkatnya partisipasi warga. Partisipasi tersebut berupa kesediaan untuk membantu pelaksanaaan program PKM dan kesediaan peternak untuk mengolah limbah ternaknya dengan bersih dan sehat. Partisipasi warga masyarakat khususnya peternak babi dalam program kegiatan ini antara lain :

a. Kehadiran pada acara sosialisasi/ penyuluhan

b. Menggali tanah

c. Membersihkan lingkungan

d. Membuat saluran limbah

e. Menjaga instalasi yang sudah terbangun

\section{PENUTUP}

Kesadaran para peternak babi Sanggrahan untuk meningkatkan kesehatan lingkungan perlu ditingkatkan agar tidak mengganggu lingkungan di sekitarnya berupa pencemaran air dan udara. Pembuangan limbah kotoran ternak ke sungai secara terbuka mengakibatkan air sungai tercemar dan udara disekitarnya bau tidak sedap karena adanya 
gas methan yang dikeluarkan dari proses pembusukan kotoran.

Pembuatan saluran limbah ternak dan biodigester sangat diperlukan untuk mengatasi hal tersebut. Di samping mengurangi dampak pencemaran lingkungan juga hasilnya berupa bio gas dan pupuk padat/cair yang diharapkan dapat dimanfaatkan oleh peternak maupun warga sekitar.

Saran, untuk perwujudan lingkungan yang bersih dan sehat, perlu peningkatan ketrampilan bagi para peternak untuk mewujudkannya. Pembuatan saluran dan biodigester pada salah satu kelompok ternak belum cukup mengatasi semua permasalahan yang ada. Namun keberhasilannya sangat diharapkan untuk memotivasi masyarakat peternak untuk menerapkannya pada masingmasing kandang. Untuk itu perlu adanya pelatihan pembuatan saluran limbah dan bio digester bagi para peternak agar dapat membuat sendiri atau bergotong royong untuk mewujudkannya di kandang dan lahan sendiri.

\section{DAFTAR PUSTAKA}

Suhut Simamora,dkk., 2006. Membuat Biogas Pengganti Bahan Baku Minyak Dan Gas Dari Kotoran Tanah Agromedia. Pustaka 2006, Jakarta.

Sulistyiyanto, Y. Dkk., 2006. Pemanfaatan Kotoran Sapi Sapi Sebagai Sumber Biogas Rumah Tangga Di Kabupaten
Julang Pisau Propensi Kalimantan

Tengah. Jurnal Widoyono Mengabdi.

Volume 15 Nomor 2.

Wahyuni, Sri, 2013, Panduan Praktis

Biogas, Penebar Swadaya, Jakarta.

, Cara Membuat Biogas dari

Kotoran Sapi, http://espeempate.

blogspot.com/2012/07 